\title{
Characterization of isolated acrosomal matrices from hamster spermatozoa*
}

\author{
H. Hyatt and R. B. L. Gwatkin \\ Reproductive and Developmental Biology, Research Institute and Gynecology, \\ The Cleveland Clinic Foundation, Cleveland, OH 44106, U.S.A.
}

\begin{abstract}
Summary. The acrosomal matrix of hamster spermatozoa was enriched and characterized. Acrosomal matrices were released from spermatozoa with shaking in a $\mathrm{pH} 5 \cdot 2$ buffer containing Triton X-100 and protease inhibitors, and enriched on a glass-bead column. Phase-contrast microscopy indicated that $70-80 \%$ of the acrosomal matrices were released from the spermatozoa and only minor contamination from sperm heads was detected. Transmission electron microscopy confirmed the low level of contamination in the preparation and revealed a bilaminar structure similar but not identical to that of guinea-pig acrosomal matrix. One- and two-dimensional SDS-polyacrylamide gel electrophoresis (SDS-PAGE) showed the acrosomal matrix to be a complex structure enriched for several polypeptides. Proteinase activity was demonstrated by gelatinSDS-PAGE. The major activity corresponded to bands of relative molecular masses $\left(M_{\mathrm{r}}\right)$ of 56000,51000 and 48000 with two minor bands of $M_{\mathrm{r}} 30000$ and 28000 . The lectin Pisum sativum agglutinin (PSA) bound to the anterior head of spermatozoa and isolated acrosomal matrix as judged by fluorescence microscopy using FITC-PSA. Western blots of spermatozoa and acrosomal matrices followed by overlay with biotinylated PSA indicated that there are at least two PSA-binding glycoproteins of $M_{\mathrm{r}}$ 60000 and 72000 .
\end{abstract}

Keywords: acrosome; acrosomal matrix; hamster spermatozoa; acrosin; proacrosin

\section{Introduction}

The acrosome is a crescent-shaped, membrane-bound vesicle situated in the anterior portion of the sperm head. It is regarded as a modified lysosome (Allison \& Hartree, 1970) or zymogen granule (Friend, 1977; Green, 1978a). The region of the acrosome bounded by the outer acrosomal membrane and inner acrosomal membrane has been termed the acrosomal matrix (Huang et al., 1985). The plasma membrane overlying the acrosome fuses with the outer acrosomal membrane to form vesicles (Bedford, 1970) during the acrosome reaction. This allows for release of components (acrosomal contents) from the interior of the acrosome. Enzymes such as hyaluronidase (Austin, 1960) and proacrosin (Meizel \& Mukerji, 1976; Huneau et al., 1984) and various glycoproteins (Kopečný \& Fléchon, 1981) are considered to be intrinsic constituents of the acrosome and are thought to function in transport of the spermatozoa through the cumulus oophorus (Cummins \& Yanagimachi, 1986), in penetration of the zona pellucida (Srivastava et al., 1965; Fraser, 1982; Talbot, 1984, 1985; Urch et al., 1985), in sperm-zona binding (Peterson et al., 1985; Primakoff et al., 1985; Saling \& Lakoski, 1985) and in sperm fusion with the egg plasma membrane (Saling et al., 1985; Primakoff et al., 1987). Although it is clear that the acrosome plays an important role in fertilization, much of the emphasis has been on the membrane proteins with little importance given

*Reprint requests to Dr R. B. L. Gwatkin. 
to the acrosomal contents other than acrosin-related events (Meizel, 1978, 1984). This has been due to the fact that the acrosomal matrix has been difficult to isolate as an intact, membrane-free structure.

Huang et al. (1985) have described a procedure for isolation of the acrosomal matrix from guinea-pig spermatozoa by taking advantage of the fact that a low $\mathrm{pH}$ buffer and trypsin inhibitors will prevent dispersal of the acrosomal matrix (Green, 1978b; Fraser, 1982; Shams-Borhan \& Harrison, 1981). We report here a modification of the procedure of Huang et al. (1985) which allows for the isolation of the acrosomal matrix from hamster spermatozoa and studies on the characterization of the enzyme and protein constituents of the acrosomal matrix.

\section{Materials and Methods}

Reagents. Chemicals for SDS-PAGE were purchased from Bio-Rad Laboratories, Richmond, CA. All other chemicals were reagent grade or better and were purchased from Sigma Chemical Co., St Louis, MO, unless otherwise indicated.

Sperm preparation. Adult male golden hamsters (Harlan Sprague-Dawley, Inc., Indianapolis, IN) were maintained on a $12 \mathrm{~h}$ light: $12 \mathrm{~h}$ dark cycle and given free access to food and water. Animals were killed with $\mathrm{CO}_{2}$ gas. The epididymides were removed, the caudae were dissected, cut into 4 pieces and the spermatozoa were extruded into $0.9 \%(\mathrm{w} / \mathrm{v}) \mathrm{NaCl}$, counted with a haemocytometer and the concentration of spermatozoa was adjusted to $1 \times 10^{8} / \mathrm{ml}$. The sperm suspension was washed in 10 volumes of $0.9 \%(\mathrm{w} / \mathrm{v}) \mathrm{NaCl}$ per $2 \times 10^{8}$ spermatozoa by centrifugation in $500 \mathrm{~g}$ for $5 \mathrm{~min}$. The resultant sperm pellets were used in subsequent procedures.

Solubilized whole spermatozoa. Spermatozoa were solubilized in $1 \%$ SDS for $30 \mathrm{~min}$ at $20^{\circ} \mathrm{C}$ in the presence of an inhibitor cocktail (see below). Spermatozoa were removed from the extract by centrifugation at $12000 \mathrm{~g}$ for $15 \mathrm{~min}$. This extract was used for protein determinations, for one- and two-dimensional SDS-polyacrylamine gel electrophoresis (SDS-PAGE), and for gelatin-SDS-PAGE.

Isolation of hamster sperm acrosomal matrices. Some minor modifications in the procedure of Huang et al. (1985) were used. All subsequent procedures were carried out on ice. The pelleted spermatozoa were resuspended in $6 \mathrm{ml}$ Solution A (Huang et al., 1985; $0.1 \mathrm{M}-\mathrm{NaCl}, 0.05 \mathrm{M}$-sodium acetate, $\mathrm{pH} 5.2$, and $0.1 \mathrm{mg}$ soybean trypsin inhibitor $/ \mathrm{ml}$ (SBTI), Type-II). Solution A also contained two additional serine protease inhibitors, SBTI, Type-I $(0 \cdot 1 \mathrm{mg} / \mathrm{ml})$ and $1 \mathrm{mM}-\mathrm{PMSF}$, the cysteine and serine protease inhibitor leupeptin $(1 \mu \mathrm{g} / \mathrm{ml}), 1 \mathrm{~mm}-p$-amino-benzamidine $(\mathrm{pAB})$, $10 \mu \mathrm{g}$ benzamidine $/ \mathrm{ml}$ and $10 \mathrm{~mm}$-EDTA (ethylenediamine-tetra-acetic acetic acid, di-sodium salt). These additional inhibitors at the final concentration indicated constituted our inhibitor cocktail. To the sperm suspension was added $2 \mathrm{ml}$ Solution B (Huang et al., 1985; $0.15 \mathrm{M}-\mathrm{NaCl}, 2.5 \%$ Triton X-100) and the inhibitor cocktail. (Final sperm concentration was $2.5 \times 10^{7} / \mathrm{ml}$.) This mixture was capped in a $15 . \mathrm{ml}$ conical tube and shaken vigorously by hand for $5 \mathrm{~min}$, releasing the acrosomal matrices from the spermatozoa. Aliquants of the sperm-acrosomal matrix mixture were assessed with phase-contrast microscopy and the numbers of spermatozoa without acrosomes per 100 total spermatozoa were counted to determine the percentage of acrosomal matrices released. The sperm concentration in this acrosomal matrix mixture (the pre-column mixture) was reduced by centrifuging the suspension for $1 \mathrm{~min}$ at $700 \mathrm{~g}$. To enrich the acrosomal matrix contents, the supernatant was passed over a glass-bead column as described by Huang et al. (1985).

Aliquants of the flow through were assessed with phase-contrast microscopy for the presence of head and/or tail contaminants and the purity of the preparation was determined by the total number of acrosomal matrices per 100 sperm components. The material collected was washed 3 times by centrifugation at $700 \mathrm{~g}$ for $10 \mathrm{~min}$ at $4^{\circ} \mathrm{C}$ in Solution A and used for transmission electron microscopy (TEM), phase and fluorescence microscopy; solubilized in 1\% SDS for $30 \mathrm{~min}$ at $20^{\circ} \mathrm{C}$ for use in protein determinations (in the absence of inhibitors); or solubilized in the presence of inhibitors and added to the appropriate sample buffer for one- and two-dimensional SDS-PAGE and for the gelatinSDS proteinase assay.

Light microscopy and photomicrography. Sperm and acrosomal matrices were observed with phase-contrast and fluorescence microscopy and photographed with a Leitz Dialux 22 microscope equipped with a 50-W mercury arc bulb for epifluorescence. FITC fluorescence was observed using a BP 450-490 excitor filter, and RKP 510 beam splitting mirror, and a 515 suppression filter (Leitz filter block I2). Phase-contrast and fluorescence photographs were taken with a Wild Photoautomatic (MPS45) camera and Kodak Tri-X Pan film (ASA 400) with the development pushed to ASA 1600.

Transmission electron microscopy. The pre-column sperm-acrosomal matrix mixture and the isolated acrosomal matrices were washed, fixed for $1 \mathrm{~h}$ in $2.5 \%$ glutaraldehyde, $0.1 \mathrm{M}$-cacodylate, $\mathrm{pH} 7.4$. After washing in cacodylate buffer, the material was post-fixed in $1 \% \mathrm{OsO}_{4}$ in cacodylate buffer, dehydrated and embedded in Epon. Silver-grey sections were cut on a Sorvall MT-5000 ultramicrotome, mounted on nickel grids and stained with $2 \%$ aqueous uranyl acetate and lead citrate. Sections were examined with a Zeiss $10 \mathrm{~A}$ electron microscope. 
Protein determinations. The sperm extract and solubilized acrosomal matrices were assayed for total soluble protein using the Pierce BCA (Bicinchoninic Acid) Protein Assay Reagent according to the supplier's instructions (Pierce Chemical Company, Rockford, IL).

Polyacrylamide gel electrophoresis (PAGE). Electrophoretic analysis using one-dimensional PAGE was performed using $1.5 \mathrm{~mm}$ thick $10 \%$ and $12 \%$ SDS-PAGE slab gels with a $5 \%$ stacking gel, according to Laemmli (1970). Gels were stained with Coomassie Blue R-250.

Two-dimensional gel electrophoresis used non-equilibrium $\mathrm{pH}$ gradient electrophoresis (NEPHGE) in the first dimension and SDS-PAGE in the second dimension according to the procedures described by O'Farrell et al. (1977). Sperm and acrosomal matrices were solubilized in NEPHGE sample buffer at a total protein concentration of $100 \mu \mathrm{g}$ per sample.

Gelatin-SDS proteinase assay. The gelatin-SDS proteinase assay (Heussen \& Dowdle, 1980; Siegel \& Polakoski, 1985; Siegel et al., 1986) was used as a means of detecting proteolytic activity. Briefly, $0.75 \mathrm{~mm}$ thick $12.5 \%$ acrylamide gels are prepared and cast as described by Laemmli (1970) except that a final concentration of $0.1 \%$ gelatin was co-polymerized in the resolving gel. Samples contained no reducing agents and they were not boiled. Samples were electrophoresed at $20 \mathrm{~mA}$ constant current at $4^{\circ} \mathrm{C}$ until the tracking dye migrated to $1 \mathrm{~cm}$ from the bottom of the gel. The gels were transferred to $2.5 \%$ Triton X-100 in water and agitated for $1 \mathrm{~h}$ to remove the SDS. Gels were washed with 4 changes of $200 \mathrm{ml}$ distilled $\mathrm{H}_{2} \mathrm{O}$ to remove the Triton X-100 and then incubated in $50 \mathrm{~mm}$-Tris buffer, $\mathrm{pH} 8.0$ for $2-3 \mathrm{~h}$ at $37^{\circ} \mathrm{C}$. The gels were fixed and stained overnight in $0.1 \%$ amido black in methanol:acetic acid:water (30:10:60 by vol.) and destained in methanol:acetic acid:water (30:10:60 by vol.).

Pisum sativum agglutinin (PSA) labelling of spermatozoa and acrosomal matrices. Spermatozoa and isolated acrosomal matrices were washed again in Solution $\mathrm{A}$ in the absence of inhibitors, fixed and permeabilized with $95 \%$ (v/v) ethanol, dried onto microscope slides and labelled with FITC-PSA according to the procedure of Cross et al. (1986). The specificity of the PSA binding was tested by labelling in the presence of the monosaccharides $\alpha$-methyl mannoside (a competitive sugar for PSA) or D-galactose (not a competitive sugar), also according to the procedure of Cross et al. (1986). The slides were mounted with gel/mount (Biomedia Corp., Foster City, CA).

Identification of PSA binding proteins after protein blotting. Sperm extract and solubilized acrosomal matrices $(100 \mu \mathrm{g})$ were boiled in non-reduced sample buffer for $5 \mathrm{~min}$. Samples were electrophoresed on $10 \%$ gels and the proteins were blotted according to the procedure of Towbin et al. (1979) onto nitrocellulose membrane (BA 85, Schleicher \& Schuell, Inc., Keane, NH) at $4^{\circ} \mathrm{C}$ for $3 \mathrm{~h}$ at $100 \mathrm{~V}$ using a Hoefer Transphor unit (Hoefer Scientific Instruments, San Francisco, CA). To detect PSA-binding polypeptides the procedure of Hawkes (1982) was modified. Biotinylated PSA $(50 \mu \mathrm{g} / \mathrm{ml})$ was applied to the blocked membrane for $30 \mathrm{~min}$ at room temperature. The membrane was washed and incubated with avidin-peroxidase for $30 \mathrm{~min}$ at room temperature. All incubations

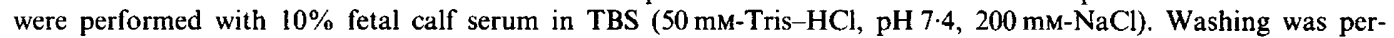
formed with TBS. The bound peroxidase was detected by the addition of $0.05 \% 3^{\prime}, 3^{\prime}$-diaminobenzadine and $0.005 \%$ hydrogen peroxide in TBS. PSA-binding polypeptides appear as dark-brown bands against a light-brown background.

\section{Results}

\section{Isolation of acrosomal matrices}

About $70-80 \%$ of the acrosomal matrix is released from the sperm head after 5 min of shaking whole spermatozoa in Solutions A + B. By phase-contrast microscopy the acrosomal crescent shape of the acrosomal matrix in the pre-column mixture is easily distinguished (Fig. 1). After the sperm-acrosomal matrix mixture is passed over the glass-bead column and centrifuged, the acrosomal matrices appear as tight aggregates and only occasional sperm heads are seen (Fig. 6c).

Routinely, $30 \mu \mathrm{g}$ soluble protein from the acrosomal matrices was obtained from $10^{8} \mathrm{sperm}$ atozoa $(0.7 \%$ of the total soluble sperm protein). In early experiments the sperm-acrosomal matrix mixture was passed over the glass-bead column without a preliminary centrifugation step to reduce the sperm concentration and only $5.6 \mu \mathrm{g}$ protein per $10^{8}$ spermatozoa $(0 \cdot 13 \%$ total protein) were obtained under these conditions, probably due to a large amount of acrosomal matrix material remaining on the column, trapped within the sperm mixture. The addition of the centrifugation step increased the protein yield of the acrosomal matrix 5-fold without increasing contamination, as judged by light microscopy and SDS-PAGE protein patterns of isolated acrosomal matrices (data not shown). 


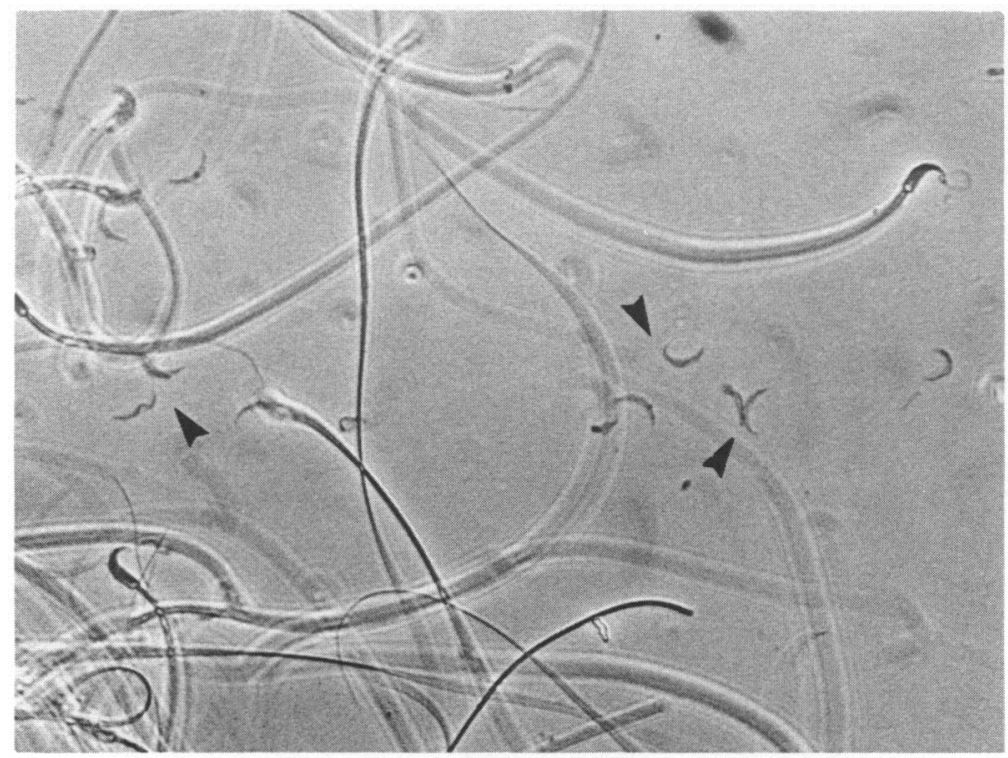

Fig. 1. Phase-contrast micrograph of a suspension of the pre-column sperm-acrosomal matrix mixture after shaking the spermatozoa for $5 \mathrm{~min}$. The released acrosomal matrices are seen as crescent-shaped, phase-dark structures (arrowheads). $\times 1600$.

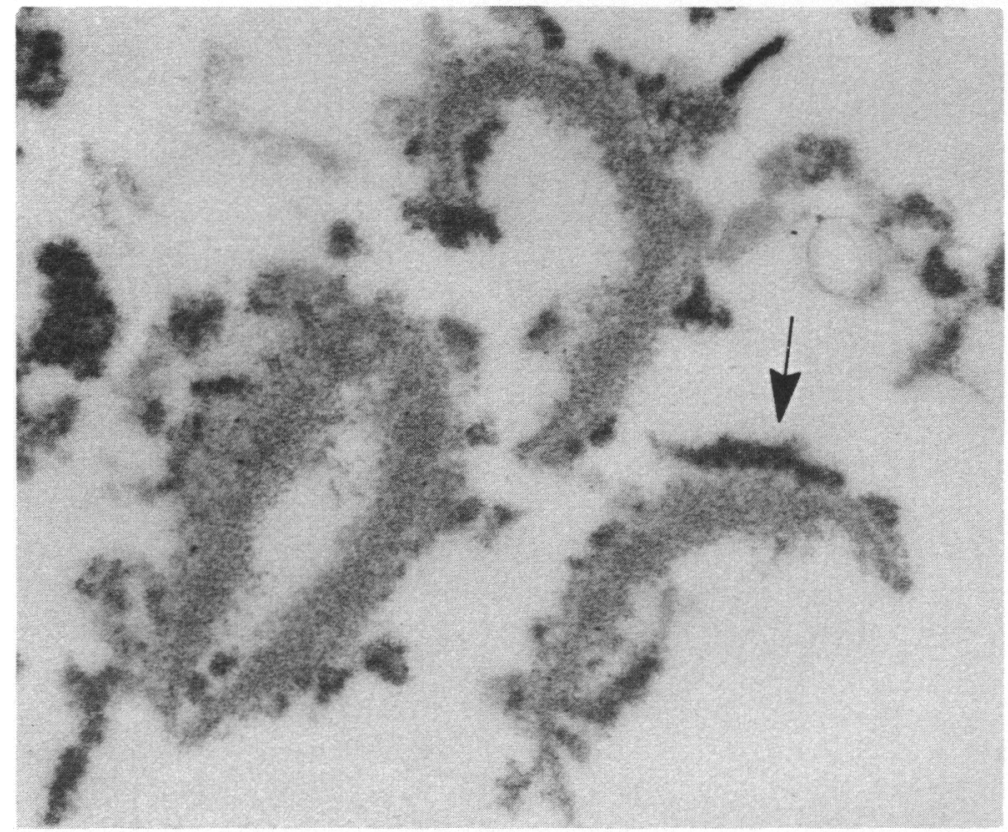

Fig. 2. Transmission electron micrograph of isolated acrosomal matrices. The acrosomal matrix appears as a crescent-shaped bilaminar structure. The outer layer is often associated with an electron-dense material (arrow). $\times 2700$. 


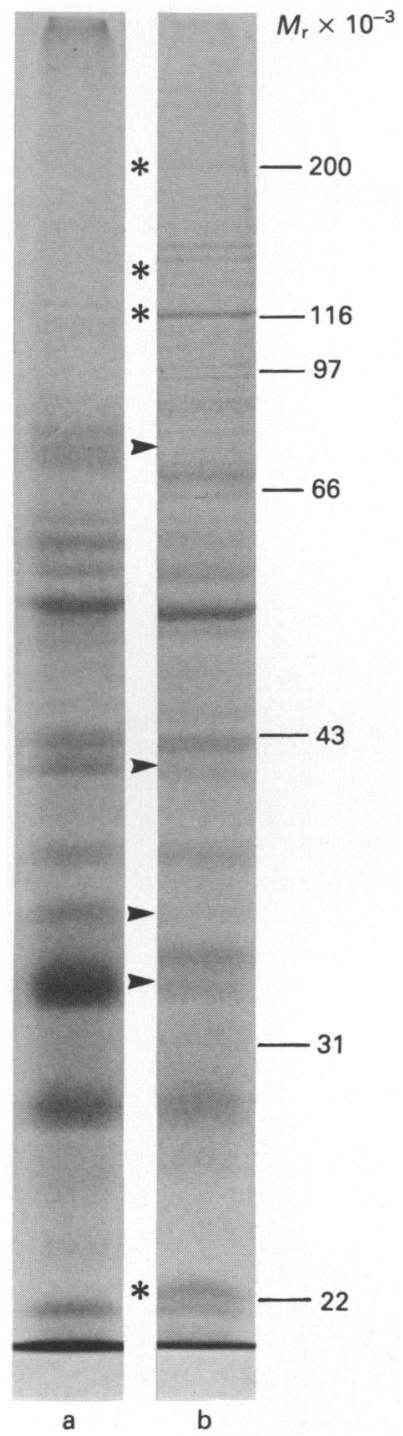

Fig. 3. Analysis of spermatozoa (a) and isolated acrosomal matrices (b) by one-dimensional SDS-PAGE. Samples $(100 \mu \mathrm{g})$ were separated on a gel containing $10 \%$ polyacrylamide and stained with coomassie blue R-250. Asterisks indicate enrichment of the acrosomal matrix for several polypeptides of $M_{\mathrm{r}}>100000$ and one of a low $M_{\mathrm{r}}$ value. Sperm polypeptides not detectable or reduced in the acrosomal matrix preparation are indicated by arrowheads.

\section{Transmission electron microscopy}

To verify the purity of the preparation and to study the ultrastructure of the acrosomal matrix, examination of the pre-column mixture and the isolated acrosomal matrix was studied by TEM. In the pre-column mixture the majority of sperm heads were free of acrosomal matrix after shaking and the released membrane-free acrosomal matrix retained the shape of the acrosomal cap. The sperm head and tail appeared intact and unaltered except for loss of membrane structure (data not shown). The isolated hamster acrosomal matrix (Fig. 2) was a membrane-free, bilaminar structure 


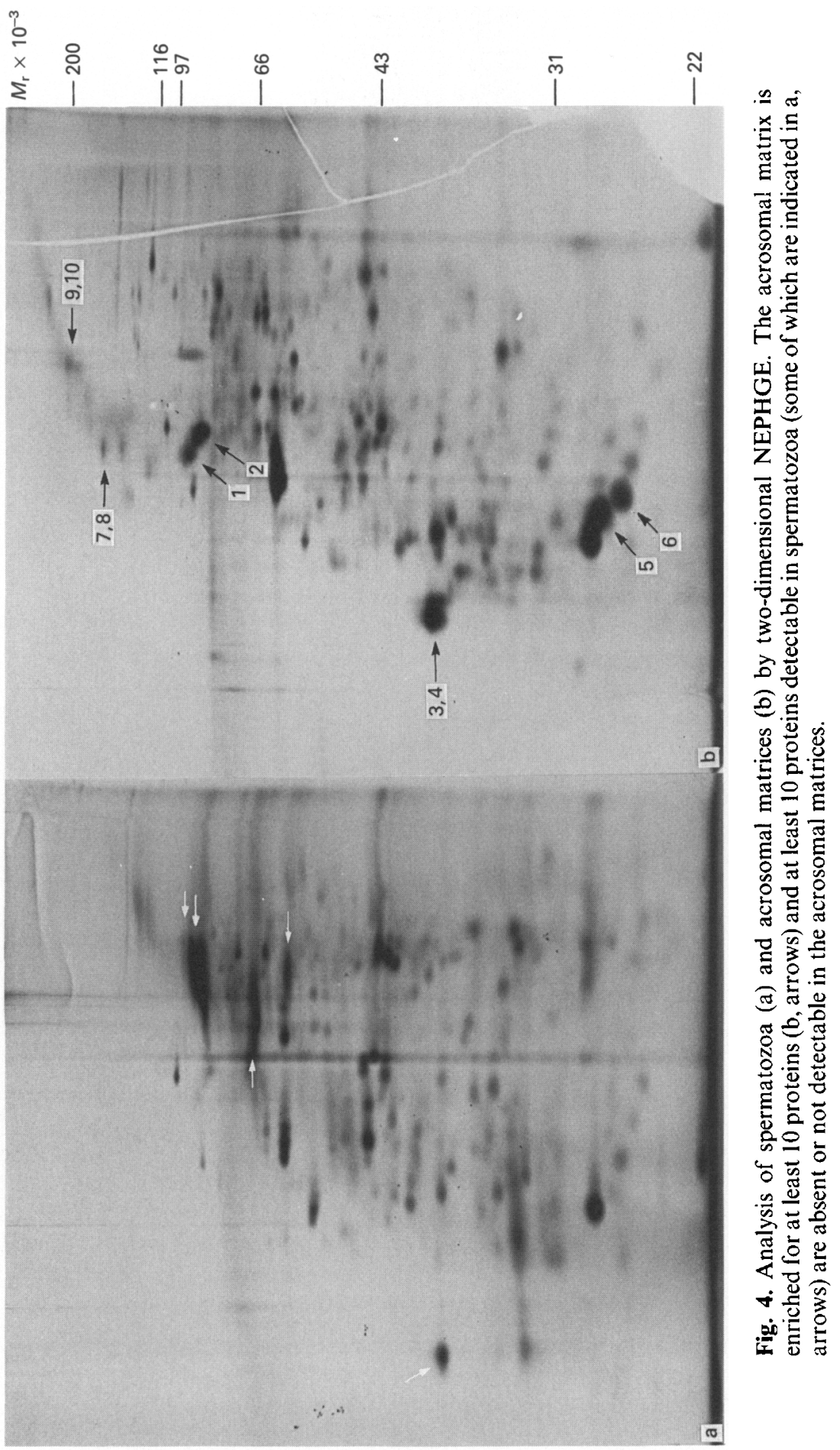




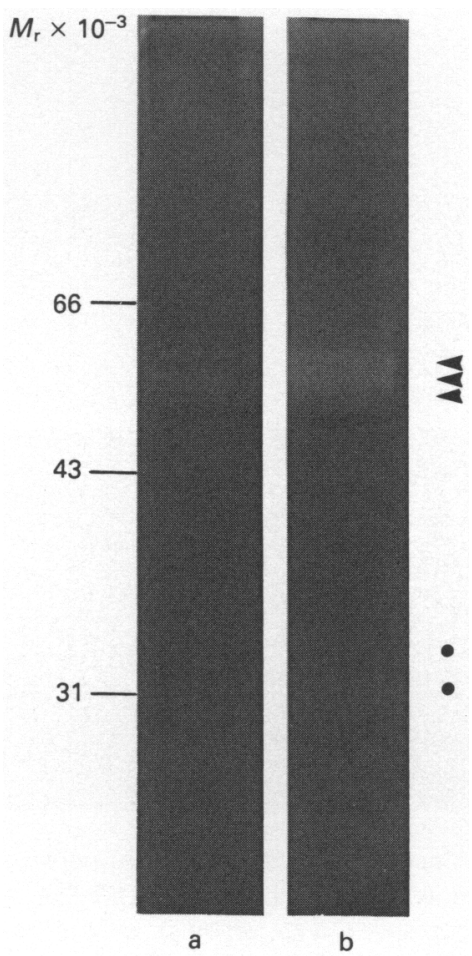

Fig. 5. Analysis of spermatozoa (a) and enriched acrosomal matrices (b) by gelatin-SDSPAGE ( $100 \mu \mathrm{g}$ protein per sample) to demonstrate protease activity. The major bands of digestion correspond to $M_{\mathrm{r}} 48000,51000$ and 56000 (arrows). The intensity of digestion is greater in the acrosomal matrix. Additional faint bands (not readily apparent in the photograph) are seen in the acrosomal matrix at $M_{\mathrm{r}} 28000$ and 30000 (dots).

which retained its acrosomal crescent shape, even after numerous centrifugations. The inner two-thirds consisted of homogeneous material that was separated by a slight gap from the outer one-third which was often associated with an electron-dense material (arrow, Fig. 2). The electrondense material in the preparations was occasionally seen as an isolated structure. Few sperm heads, tail components or membranous structures were present in the isolated acrosomal matrix pellet, indicating that the preparation was enriched for acrosomal matrices.

\section{Analysis of acrosomal matrices by SDS-PAGE}

The isolated acrosomal matrix was compared with solubilized whole sperm proteins by onedimensional SDS-PAGE. The protein pattern was highly complex and similar to that of total soluble sperm proteins. When compared with an equal protein load of spermatozoa (Fig. 3) the acrosomal matrix was enriched for several proteins of high relative molecular mass $\left(M_{\mathrm{r}}\right)>100000$, as well as for a band of $M_{\mathrm{r}} 20000$. The acrosomal matrix lacked or had a lower concentration of 4 sperm proteins of $M_{\mathrm{r}} 30000,35000,40000$ and 80000 .

The differences between the spermatozoa and acrosomal matrix was further elucidated on silver-stained two-dimensional NEPHGE gels. The acrosomal matrix was enriched for at least 10 proteins (Fig. 4) and at least 10 proteins detectable in spermatozoa were absent in the acrosomal matrix. 

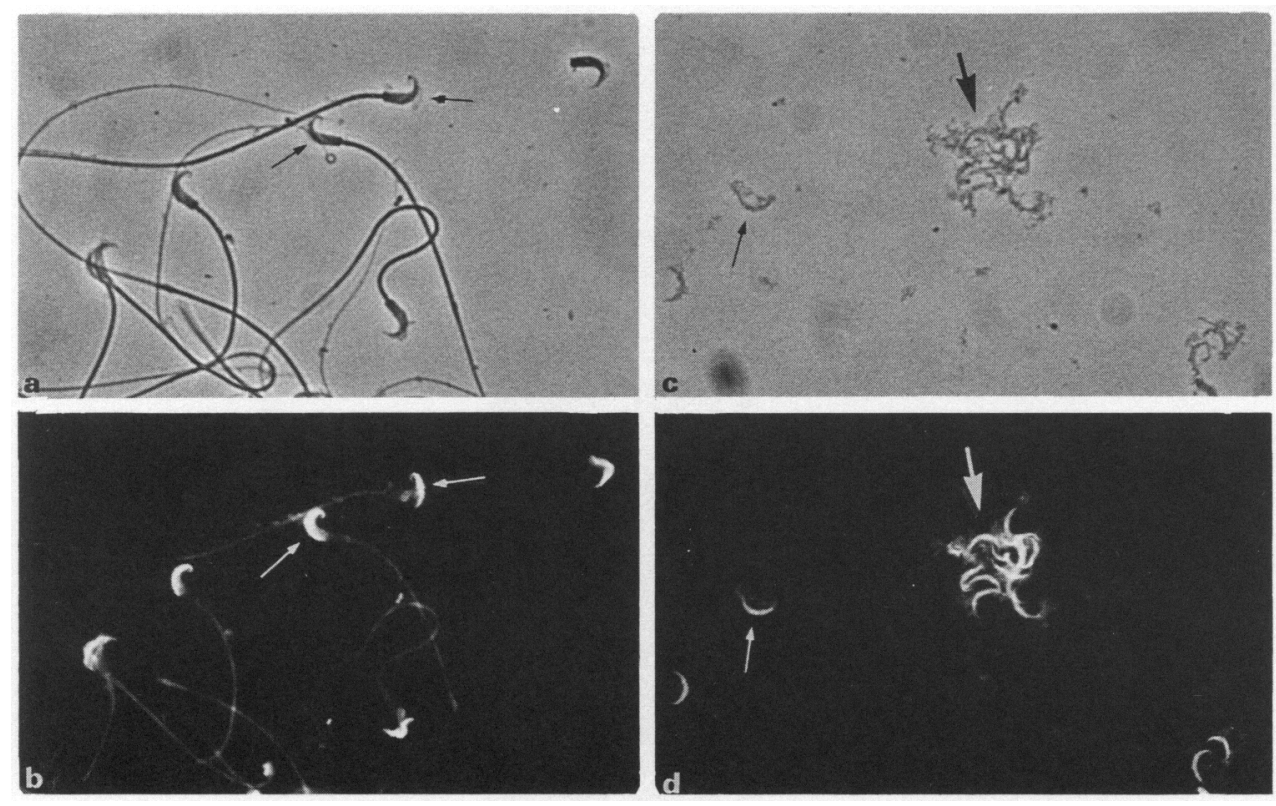

Fig. 6. Phase $(a, c)$ and fluorescence $(b, d)$ micrographs of permeabilized hamster spermatozoa $(a, b)$ and isolated acrosomal matrices (c, d) labelled with FITC-PSA. Intense labelling is seen over the anterior head of the spermatozoa (b, arrows). In (c), the crescent shape of the acrosomal matrix is not distinct in the clusters (large arrow) but it is clear in (d) due to the specificity of the PSA for the acrosomal matrix. The crescent shape is also apparent in single acrosomal matrices (small arrow). $\times 1900$.

\section{Gelatin-SDS proteinase assay}

The gelatin-SDS proteinase assay was used to confirm that the enriched acrosomal matrix material was still enzymically active after the isolation procedure as well as being enriched for proteinase activity that would be suggestive of acrosomal material (proacrosin-acrosin for instance). The results in Fig. 5 show that equal amounts of spermatozoa and acrosomal matrix protein demonstrate major bands of digestion corresponding to $M_{\mathrm{r}}$ values of 48000,51000 and 56000 . However, the intensity of digestion was greater in the acrosomal matrix. The bands of $M_{\mathrm{r}}$ 48 000-50000 were coincident with purified hamster proacrosin (Siegel et al., 1986). Additional faint bands (not readily detectable in the figure) were seen for acrosomal matrix material at $M_{\mathrm{r}}$ values of 28000 and 30000 .

\section{PSA binding to spermatozoa and acrosomal matrices}

Hamster spermatozoa permeabilized in ethanol and labelled with FITC-PSA have intensely fluorescent acrosomal regions (Fig. 6b). When tested for binding specificity, $\alpha$-methyl glucoside reduced labelling with FITC-PSA to undetectable levels while D-galactose had no effect (data not shown). Permeabilized acrosomal matrices were intensely labelled with FITC-PSA (Fig. 6d). The aggregation that occurred after centrifugation obscured the distinct shape of the acrosomal matrix (Fig. 6c), but the preservation of the crescent shape was readily distinguishable with fluorescence microscopy (Fig. 6d). This is further confirmation that PSA binds to the contents of the acrosome. 


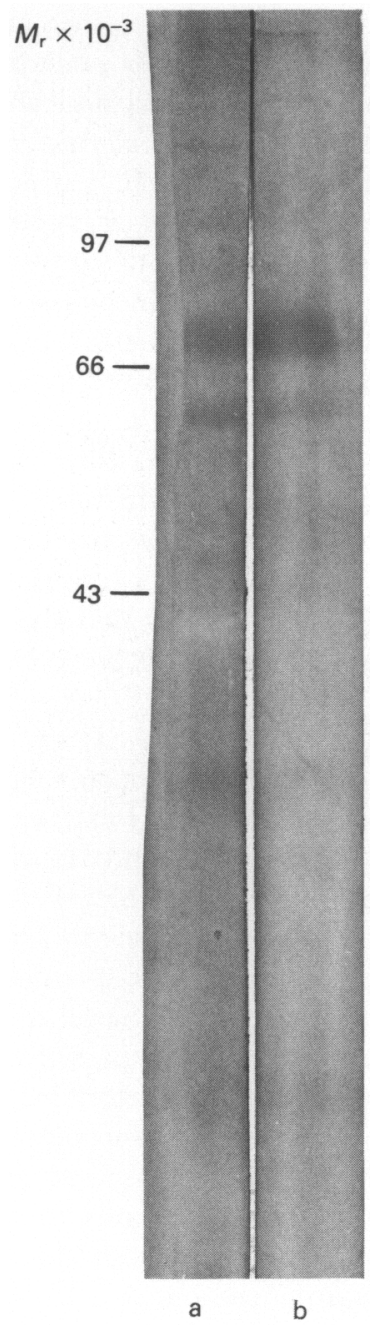

Fig. 7. Western blot of spermatozoa (a) and acrosomal matrices (b) overlayed with PSA. The lectin binds strongly to 2 glycoproteins of $M_{\mathrm{r}} 60000$ and 72000 .

PSA overlay

Western blots of spermatozoa and acrosomal matrix followed by PSA overlay, showed two major PSA-binding proteins of $M_{\mathrm{r}} 60000$ and 72000 (Fig. 7). No binding was detected in the presence of $\alpha$-methyl glucoside or when biotinylated PSA was omitted (data not shown).

\section{Discussion}

We have used minor modifications of the procedure of Huang et al. (1985) to isolate an enriched preparation of acrosomal matrices from hamster spermatozoa. We used additional protease inhibitors and a centrifugation step before enrichment of the acrosomal matrices on a glass-bead column. Phase-contrast microscopy showed that $70-80 \%$ of the acrosomal matrix is released from the spermatozoa after shaking and these released acrosomal matrices have an acrosomal crescent 
shape. The crescent shape of the acrosomal matrix is retained in the enriched preparation and TEM analysis verifies that the glass-bead column produces a preparation highly enriched for acrosomal matrices. The acrosomal matrix of hamster spermatozoa is easily isolated from whole spermatozoa in quantities sufficient for enzyme assays and protein characterization.

By TEM the acrosomal matrix appears as a bilaminar structure that is similar but not identical to that described by Huang et al. (1985). The outer layer is often associated with an electron-dense material. This material is intrinsic to spermatozoa and is probably the electron-dense material that is associated with the outer acrosomal membrane in bull spermatozoa (Olson et al., 1985) and guinea-pig, hamster, rabbit and rat spermatozoa (Winfrey et al., 1987): these authors found that extraction of the membrane-associated complex with Triton X-100 solubilizes the outer acrosomal membrane, but the electron-dense material (termed the acrosomal lamina) remains intact.

Huang et al. (1985) and Stojanoff et al. (1987) have described methods for isolating the acrosomal matrix from guinea-pig spermatozoa. Their studies concentrate on the enzyme contents of the acrosomal matrix with no emphasis on other proteins or their functions. It is assumed that the proteinase content of the acrosomal matrix is of primary importance. However, analysis by one- and two-dimensional SDS-PAGE indicates that the acrosomal matrix is a surprisingly complex structure, suggesting that it may play a more complex role in fertilization than just digestion of the cumulus or zona.

Analysis of the acrosomal matrix by the gelatin-SDS proteinase assay reveals an increased activity over whole spermatozoa for bands of a molecular weight that are coincident with purified proacrosin. This suggests that the isolated acrosomal matrices are stable with respect to enzyme activity since the majority of the proteinase in the proacrosin-acrosin system is in the inactive zymogen form, proacrosin (Meizel \& Mukerji, 1976; Siegel et al., 1986). Two additional bands of $M_{\mathrm{r}} 28000$ and 30000 that are not apparent in the sperm preparation were present in the acrosomal matrix and may be active acrosin, or part of the sperminogen-spermin system that has been identified in the spermatozoa of boars and humans (Siegel \& Polakoski, 1984; Siegel et al., 1986, 1987). We have not yet tried to extract the acrosomal matrix with acid, nor have we activated the matrix in the absence of protease inhibitors to determine the acrosin content. Therefore, the proteinase profile of the acrosomal matrix may be more complex than reported here.

The lectin PSA binds the anterior head of permeabilized hamster spermatozoa and acrosomal matrix, adding further evidence that PSA has an affinity for the acrosomal contents as reported by Cross et al. (1986) for human spermatozoa. Western blots indicate that there are at least two PSA-binding proteins in the acrosomal matrix, but it is likely that more than two PSA-binding polypeptides exist. Studies are in progress to test for PSA binding with unboiled and reduced preparations and to determine whether any of these correspond to the enriched proteins apparent on two-dimensional NEPHGE. We hope to exploit these binding characteristics by applying PSAaffinity chromatography to solubilized hamster acrosomal matrices as a means of isolating glycoproteins from acrosomal matrices. This will lead to studies of the role the acrosomal matrix plays in gamete binding and other fertilization mechanisms.

We thank Dr Joanne Conover for her advice and criticism and Ms Chris Caruloff for typing the manuscript.

\section{References}

Allison, A.C. \& Hartree, E.F. (1970) Lysozomal enzymes in the acrosome and their possible role in fertilization. J. Reprod. Fert. 21, 501-515.

Austin, C.R. (1960) Capacitation and the release of hyaluronidase from spermatozoa. J. Reprod. Fert. 1, $310-311$.
Bedford, J.M. (1970) Sperm capacitation and fertilization in mammals. Biol. Reprod., Suppl. 2, 128-158.

Cross, N.L., Morales, P., Overstreet, J.W. \& Hanson, F.W. (1986) Two simple methods for detecting acrosome-reacted human spermatozoa. Gamete Res. $15,213-226$. 
Cummins, J.M. \& Yanagimachi, R. (1986) Development of ability to penetrate the cumulus oophorus by hamster spermatozoa capacitated in vitro, in relation to the timing of the acrosome reaction. Gamete Res. $15,187-212$.

Fraser, L.R. (1982) p-Aminobenzamidine, an acrosin inhibitor, inhibits mouse sperm penetration of the zona pellucida but not the acrosome reaction. $J$. Reprod. Fert. 65, 185-194.

Friend, D.S. (1977) The organization of the spermatozoal membrane. In Immunobiology of Gametes, pp. 5-30. Eds M. Edidin \& M. H. Johnson. Cambridge University Press, Cambridge.

Green, D.P.L. (1978a) The mechanism of the acrosome reaction. In Development in Mammals, Vol. 3, pp. 65-81. Ed M. H. Johnson. Elsevier/North Holland, Amsterdam.

Green, D.P.L. (1978b) The activation of proteolysis in the acrosome reaction of guinea pig sperm. $J$. Cell Sci. 32, 53-164.

Hawkes, R. (1982) Identification of concanavalin Abinding proteins after sodium dodecyl sulfate-gel electrophoresis and protein blotting. Analyt. Biochem. 123, 143-146.

Heussen, C. \& Dowdle, E.D. (1980) Electrophoretic analysis of plasminogen activators in polyacrylamide gels containing sodium dodecyl sulfate and copolymerized substrates. Analyt. Biochem. 102, 196-202.

Huang, T.T.F., Jr, Hardy, D., Yanagimachi, H., Teuscher, C., Tung, K., Wild, G. \& Yanagimachi, $R$. (1985) $\mathrm{pH}$ and protease control of acrosomal content stasis and release during the guinea pig sperm acrosome reaction. Biol. Reprod. 32, 451-462.

Huneau, D., Harrison, R.A.P. \& Flechon, J.E. (1984) Ultra-structural localization of proacrosin and acrosin in ram spermatozoa. Gamete Res. 9, 425-440.

Kopeč́n, V. \& Fléchon, J.E. (1981) Fate of acrosomal glycoproteins during the acrosome reaction and fertilization: a light and electron microscope autoradiographic study. Biol. Reprod. 24, 201-216.

Laemmli, U.K. (1970) Cleavage of structural proteins during assembly of the head of bacteriophage T4. Nature, Lond. 227, 680-685.

Meizel, S. (1978) The mammalian sperm acrosome reaction, a biochemical approach. In Development in Mammals, Vol. 3, pp. 1-64. Ed. M. H. Johnson. Elsevier North. Holland, Amsterdam.

Meizel, S. (1984) The importance of hydrolytic enzymes to an exocytotic event: The mammalian sperm acrosome reaction. Biol. Rev. 59, 125-157.

Meizel, S. \& Mukerji, S.K. (1976) Biochemical studies of proacrosin and acrosin from hamster cauda epididymal spermatozoa. Biol. Reprod. 14, 444450.

O'Farrell, P.Z., Goodman, H.M. \& O'Farrell, P.H. (1977) High resolution two-dimensional electrophoresis of basic as well as acidic proteins. Cell 12, $1133-1142$.

Olson, G.E., Winfrey, V.P., Garbers, D.L. \& Noland, T.D. (1985) Isolation and characterization of a macromolecular complex associated with the outer acrosomal membrane of bovine spermatozoa. Biol. Reprod. 33, 761-779.

Peterson, R.N., Henry, L., Hunt, W., Saxena, N. \& Russell, L.D. (1985) Further characterization of boar spermatozoa plasma membrane proteins with affinity for the porcine zona pellucida. Gamete Res. $12,91-100$.

Primakof, P., Hyatt, H. \& Myles, D.G. (1985) A role for the migrating sperm surface antigen $\mathrm{pH}-20$ in guinea pig sperm binding to the egg zona pellucida. $J$. Cell Biol. 101, 2239-2244.

Primakoff, P., Hyatt, H. \& Tredick-Kline, J. (1987) Identification of a sperm surface protein with a potential role in sperm-egg fusion. J. Cell Biol. 104, 141-149.

Saling, P.M. \& Lakoski, K.A. (1985) Mouse spermatozoa antigens that participate in fertilization. II. Inhibition of sperm penetration through the zona pellucida using monoclonal antibodies. Biol. Reprod. 33, 527-536.

Saling, P.M., Irons, G. \& Waibel, R. (1985) Mouse sperm antigens that participate in fertilization. 1. Inhibition of sperm fusion with the egg plasma membrane using monoclonal antibodies. Biol. Reprod. 33, 515-526.

Shams-Borhan, G. \& Harrsion, R.A.P. (1981) Production, characterization and use of ionophore-induced, calcium-dependent acrosome reaction in ram spermatozoa. Gamete Res. 4, 407-432.

Siegel, M.S. \& Polakoski, K.L. (1984) Human sperminogen: Purification and properties of a unique sperm proteinase zymogen. Fedn Proc. Fedn Am. Socs exp. Biol. 43, 2066.

Siegel, M.S. \& Polakoski, K.L. (1985) Evaluation of the human sperm proacrosin-acrosin system using gelatinsodium dodecyl sulfate-polyacrylamide gel electrophoresis. Biol. Reprod. 32, 713-720.

Siegel, M.S., Bechtold, D.S., Kopta, C.I. \& Polakoski, K.L. (1986) Quantification and partial characterization of the hamster sperm proacrosin-acrosin system. Biol. Reprod. 35, 485-491.

Siegel, M.S., Bechtold, D.S., Willand, J.L. \& Polakoski, K.L. (1987) Partial purification and characterization of human sperminogen. Biol. Reprod. 36, 1063-1068.

Strivastava, P.N., Adams, C.E. \& Hartree, E.F. (1965) Enzymatic action of acrosomal preparations on the rabbit ovum in vitro. J. Reprod. Fert. 10, 61-67.

Stojanoff, A., Bourne, H., Andrews, A.G. \& Hyne, R.V. (1987) Isolation of a stable apical segment of the Guinea pig sperm acrosome. Gamete Res. 17, 321-332.

Talbot, P. (1984) Hyaluronidase dissolves a component in the hamster zona pellucida. J.exp. Zool. 229, 309-316.

Talbot, P. (1985) Sperm penetration through oocyte investments in mammals. Am. J. Anat. 174, 331-346.

Towbin, H., Stachelin, T. \& Gordon, J. (1979) Electrophoretic transfer of proteins from polyacrylamide gels to nitrocellulose sheets: procedure and some applications. Proc. natn. Acad. Sci. U.S.A. 76, 4350- 4354.

Urch, U.A., Wardrip, N.J. \& Hedrick, J.L. (1985) Limited and specific proteolysis of the zona pellucida by acrosin. J. exp. Zool. 233, 479-483.

Winfrey, V.P., Carter, C.E. \& Olson, G.E. (1987) The mammalian sperm outer acrosomal membrane: evidence for common antigenic determinants between species. J. Cell Biol. 105, 169a, Abstr. 